\title{
Metabolic evolution of Corynebacterium glutamicum for increased production of L-ornithine
}

\author{
Ling-Yan Jiang, Shang-Guang Chen, Yuan-Yuan Zhang and Jian-Zhong Liu*
}

\begin{abstract}
Background: L-ornithine is effective in the treatment of liver diseases and helps strengthen the heart. The commercial applications mean that efficient biotechnological production of L-ornithine has become increasingly necessary. Adaptive evolution strategies have been proven a feasible and efficient technique to achieve improved cellular properties without requiring metabolic or regulatory details of the strain. The evolved strains can be further optimised by metabolic engineering. Thus, metabolic evolution strategy was used for engineering Corynebacterium glutamicum to enhance L-ornithine production.
\end{abstract}

Results: A C. glutamicum strain was engineered by using a combination of gene deletions and adaptive evolution with 70 passages of growth-based selection. The metabolically evolved C. glutamicum strain, named $\triangle A P E 6937 R 42$, produced $24.1 \mathrm{~g} / \mathrm{L}$ of L-ornithine in a 5 - L bioreactor. The mechanism used by C. glutamicum $\triangle$ APE6937R42 to produce L-ornithine was investigated by analysing transcriptional levels of select genes and NADPH contents. The upregulation of the transcription levels of genes involved in the upstream pathway of glutamate biosynthesis and the elevated NADPH concentration caused by the upregulation of the transcriptional level of the ppnK gene promoted L-ornithine production in C. glutamicum $\triangle$ APE6937R42.

Conclusions: The availability of NADPH plays an important role in L-ornithine production in C. glutamicum. Our results demonstrated that the combination of growth-coupled evolution with analysis of transcript abundances provides a strategy to engineer microbial strains for improving production of target compounds.

Keywords: L-Ornithine, Corynebacterium glutamicum, Adaptive evolution, Metabolic engineering, Transcriptional level analysis

\section{Background}

L-ornithine, a non-essential amino acid and an important constituent of the urea cycle, is the precursor of other amino acids, such as citrulline and arginine. It is effective for the treatment and prophylaxis of liver diseases [1], and has also been applied to wound healing [2]. Recently, it was demonstrated that L-ornithine supplementation increased serum levels of growth hormone and insulin-like growth factor-1 after heavy-resistance exercise in strength-trained athletes [3]. Many studies have reported that high yields of L-ornithine can be produced from a citrulline- or arginine-requiring mutant of

\footnotetext{
* Correspondence: Issljz@mail.sysu.edu.cn

Biotechnology Research Centre and Biomedicine Centre, School of Life Sciences, Sun Yat-sen University, Guangzhou 510275, People's Republic of
} China

\section{Biomed Central}

(c) 2013 Jiang et al.; licensee BioMed Central Ltd. This is an Open Access article distributed under the terms of the Creative Commons Attribution License (http://creativecommons.org/licenses/by/2.0), which permits unrestricted use, distribution, and reproduction in any medium, provided the original work is properly cited. a coryneform bacterium obtained by classical mutagenesis [4-7]. Although this mutant can produce a high yield of L-ornithine, its culture is unstable owing to reversion of the auxotrophic phenotype, which causes the production of L-ornithine to drop markedly.

Several recent reports have described progress in metabolic engineering of microorganisms for L-ornithine production. Lee and Cho reported that an engineered Escherichia coli produced $13.2 \mathrm{mg}$ L-ornithine per gram of dry cell weight (DCW), and that addition of glutamate to the culture favoured L-ornithine production in the engineered E. coli [8]. Hwang et al. reported that cooverexpression of $\arg C J B D$ in a triple-gene knockout strain C. glutamicum ATCC 13032 ( $\triangle \operatorname{argF\Delta argR\Delta proB)}$ resulted in a cellular L-ornithine content of $16.49 \mathrm{mg} / \mathrm{g}$ $\mathrm{DCW}$ and a concentration of L-ornithine in the culture 
medium of $179.14 \mathrm{mg} / \mathrm{L}$ [9]. Proline can be converted into L-ornithine by ornithine cyclodeaminase, which is a key enzyme responsible for enhancing L-ornithine production by $C$. glutamicum in proline-supplemented media [10]. Huang and Cho reported that over-expression of the Ncgl1469 open reading frame, exhibiting $\mathrm{N}$-acetylglutamate synthase activity, increased L-ornithine production in C. glutamicum by 39\% [11]. Recently, the same workers deleted the gluconate kinase gene gntK of C. glutamicum ATCC 13032 ( $\triangle \operatorname{argF\Delta argR)}$ to obtain C. glutamicum SJC8399, which produced $13.16 \mathrm{~g} / \mathrm{L}$ of L-ornithine [12]. The L-ornithine producing strain C. glutamicum ATCC 13032 ( $\triangle \operatorname{argF} \triangle \operatorname{argR})$ named ORN1 was constructed and shown to produce L-ornithine from arabinose when araBAD from $E$. coli was expressed [13]. Recently, this group also constructed an engineered $C$. glutamicum ORN1 (pEKEx3- $x y l A_{X c}-x y l B_{C g}$ ) to effectively produce Lornithine from xylose [14]. In our previous paper [15], we constructed a strain of C. glutamicum in which three genes had been deleted. This strain, named ATCC13032 $(\Delta \operatorname{argF} \Delta p r o B \Delta k g d)$, produced L-ornithine of $18.17 \mathrm{~g} / \mathrm{L}$ in the optimal medium [16].

Adaptive evolution strategies have been proven a feasible and efficient technique to achieve improved cellular properties without requiring metabolic or regulatory details of the strain [17-20]. The defining feature of adaptive evolution involves applying a selection pressure that favours the growth of mutants with the traits of interest. Growth-coupled adaptive evolution can significantly increase yields [21]. When combined with metabolic engineering, adaptive evolution is known as metabolic evolution engineering. The evolved strains can be further optimised by metabolic engineering. Metabolic evolution has been successfully employed for the improved production of succinate [20,22], L-alanine [23], and dihydroxyacetone [24]. However, to our knowledge, metabolic evolution engineering has never been reported to boost the production of L-ornithine.

In this study, we first deleted the speE gene of $C$. glutamicum ATCC 13032 ( $\triangle \arg F \Delta p r o B$ ) to obtain $C$.

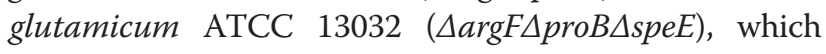

was then modified using growth-coupled adaptive evolution to improve L-ornithine production. After comparing the transcriptional levels of select genes of the evolved strain with those of the parent strain, additional genetic modifications were introduced to the evolved strain to further improve L-ornithine production. The mechanism of L-ornithine production by the metabolic evolved strain was also investigated by analysing transcriptional levels of genes of interest, as well as NADPH concentrations.

\section{Results}

\section{Construction of the triple gene deletion C. glutamicum for adaptive evolution}

In our previous paper [15], proteomic analysis demonstrated that the spermidine synthase encoded by the speE gene was more abundant in C. glutamicum engineered to overproduce L-ornithine than in wild-type C. Glutamicum. The upregulation might result in the degradation of L-ornithine. Thus, we deleted the speE gene of C. glutamicum ( $\triangle \operatorname{argF} \triangle p r o B)$ to obtain C. glutamicum $\triangle \mathrm{APE}$. As expected, the deletion of the speE gene enhanced L-ornithine production. The $C$. glutamicum $\triangle \mathrm{APE}$ strain produced $11.3 \pm 0.3 \mathrm{~g} / \mathrm{L}$ of L-ornithine, which is higher than that of C. glutamicum ( $\triangle \operatorname{argF} \Delta$ proB) $(10.2 \pm 0.2 \mathrm{~g} / \mathrm{L}$; Table 1$)$. Thus, $C$. glutamicum $\triangle \mathrm{APE}$ was used as the parent strain for adaptive evolution.

\section{Adaptive evolution}

To improve L-ornithine production, C. glutamicum $\triangle \mathrm{APE}$ was subjected to adaptive evolution driven by growth-based selection. This process comprised two stages (Figure 1). First, glucose and L-ornithine were added into the fermentation medium to overcome their inhibitions for growth and overproduction of metabolite. Screening a mutant resistant to substrate and end product is one common strategy for strain improvement by classical mutagenesis. At the later stage, only glucose was added at gradually increasing levels, and no L-ornithine was needed. After 70 days of adaptive evolution, one of the clones, referred to as C. glutamicum $\triangle \mathrm{APE}$ 6937, was

Table 1 L-Ornithine production by different strains

\begin{tabular}{|c|c|c|c|}
\hline Strain & $\mathrm{OD}_{600}$ & $\begin{array}{l}\text { L-Ornithine } \\
\text { concentration (g/L) }\end{array}$ & $\begin{array}{l}\text { L-Ornithine } \\
\text { content (g/g DCW) }\end{array}$ \\
\hline C. glutamicum (UargFAproB) & $20.1 \pm 0.7$ & $10.2 \pm 0.2$ & $1.8 \pm 0.1$ \\
\hline C. glutamicum $\triangle A P E$ & $18.5 \pm 0.3^{*}$ & $11.3 \pm 0.3^{*}$ & $2.2 \pm 0.2^{*}$ \\
\hline C. glutamicum $\triangle$ APE6937 & $23.5 \pm 1.4^{*}$ & $13.6 \pm 0.5^{*}$ & $2.1 \pm 0.1$ \\
\hline C. glutamicum $\triangle$ APE6937(pEC-XK99E) & $28.0 \pm 1.2^{\#}$ & $12.2 \pm 0.3^{\#}$ & $1.6 \pm 0.1^{\#}$ \\
\hline C. glutamicum $\triangle A P E 6937\left(p E C-\arg B_{c g}\right)$ & $24.5 \pm 1.0^{\#}$ & $14.3 \pm 0.5^{\#}$ & $2.1 \pm 0.2^{\#}$ \\
\hline C. glutamicum $\triangle A P E 6937\left(p E C-\arg B_{e d}\right)$ & $22.6 \pm 1.9^{\#}$ & $13.1 \pm 0.2^{\#}$ & $2.1 \pm 0.2^{\#}$ \\
\hline C. glutamicum $\triangle A P E 6937 R 42$ & $22.7 \pm 0.1^{*}$ & $17.3 \pm 0.4^{*}$ & $2.7 \pm 0.2^{*}$ \\
\hline
\end{tabular}

*Significantly different from the parent strain. "Significantly different from $\triangle$ APE6937(pEC-XK99E). 


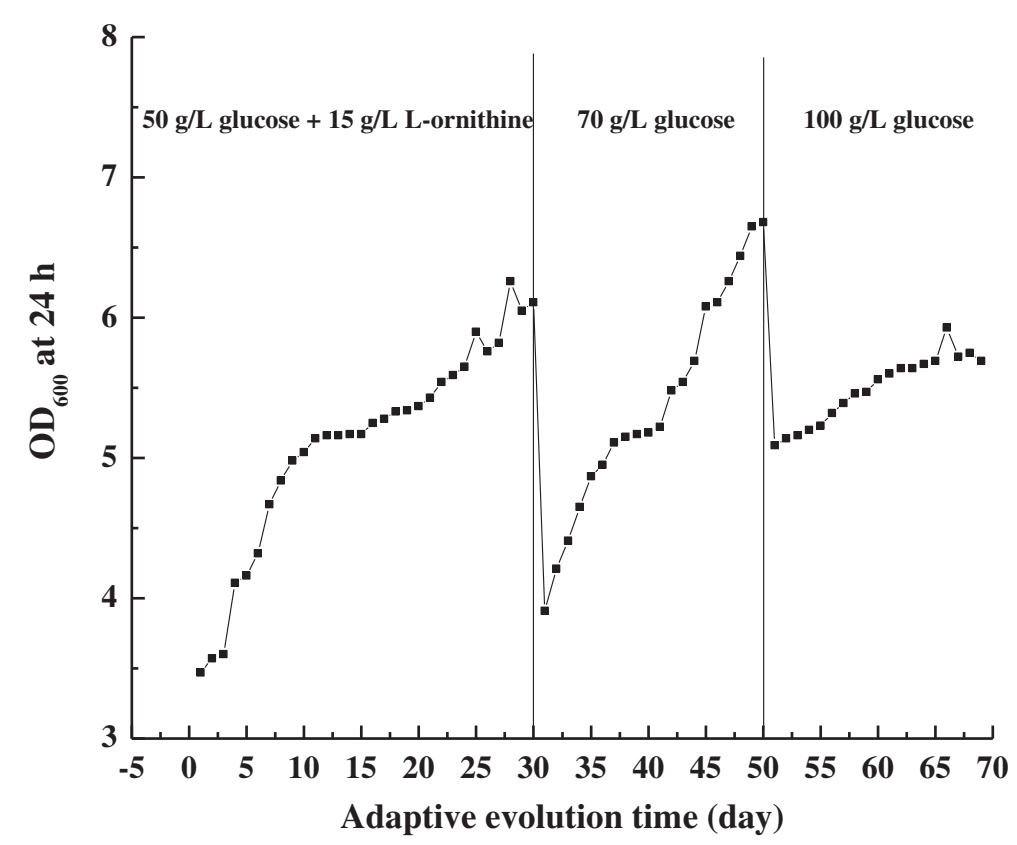

Figure 1 Growth of C. glutamicum (UargFAproBAspeE) during adaptive evolution.

chosen for further study. The C. glutamicum $\triangle \mathrm{APE} 6937$ strain produced $13.6 \pm 0.5 \mathrm{~g} / \mathrm{L}$ of L-ornithine. The yield was about $20 \%$ higher than that of the parent strain $C$. glutamicum $\triangle \mathrm{APE}(11.3 \pm 0.3 \mathrm{~g} / \mathrm{L}$; Table 1$)$. However, the L-ornithine content of the evolved strain C. glutamicum $\triangle$ APE 6937 was similar to that of the parent strain $C$. glutamicum $\triangle \mathrm{APE}$. This suggests that the increased Lornithine level of the evolved strain C. glutamicum $\triangle \mathrm{APE}$ 6937 is caused by the increased cell density.

\section{Characterisation of the evolved strain using qRT-PCR and sequence analysis}

In order to understand the mechanism of the increased L-ornithine level in the evolved strain, we analysed the transcriptional levels of genes that encode enzymes involved in L-ornithine biosynthesis in the evolved strain C. glutamicum $\triangle \mathrm{APE6937.} \mathrm{These} \mathrm{genes} \mathrm{comprise} \mathrm{pgi}$ (encoding glucose-6-phosphate isomerase), $p f k A$ (encoding 6-phosphofructokinase), gap (encoding glyceraldehyde-3-phosphate dehydrogenase), pyk (encoding pyruvate kinase), pyc (encoding pyruvate carboxylase), gltA (encoding citrate synthase), gdh (encoding glutamate dehydrogenase), $\arg B$ (encoding acetylglutamate kinase) and $\arg J$ (encoding the bifunctional ornithine acetyltransferase $/ \mathrm{N}$-acetylglutamate synthase). And then we compared the data with that obtained in the parent strain C. glutamicum $\triangle \mathrm{APE}$. The results are presented in Figure 2A. All of these genes in the evolved strain
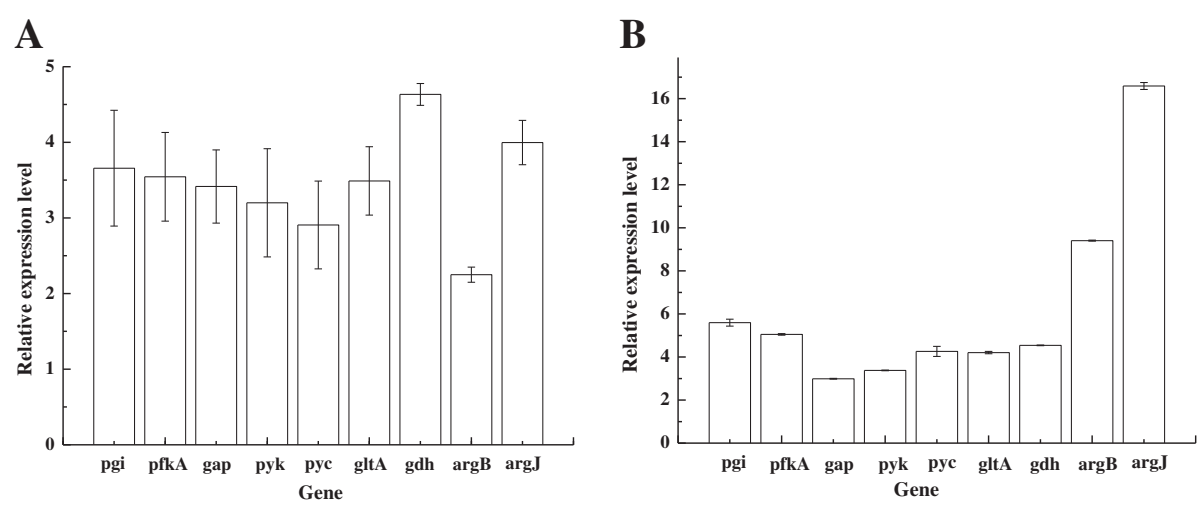

Figure 2 Levels of select transcripts in the evolved strains C. glutamicum $\triangle$ APE6937 (A) and C. glutamicum $\triangle A P E 6937 R 42$ (B) compared with those of the parent strain C. glutamicum $\triangle \mathrm{APE}$ at $\mathbf{5 4} \mathbf{~ h}$ in shake flasks. Abundances of each transcript in $\triangle \mathrm{APE} 6937$ or $\triangle \mathrm{APE} 6937 \mathrm{R} 42$, determined using qRT-PCR, were normalised relative to levels of the same transcript in the parental strain. 
C. glutamicum $\triangle \mathrm{APE} 6937$ are upregulated, with the smallest degree of upregulation seen for the $\arg B$ gene.

In an attempt to identify mutations that confer the high-yield phenotype, we sequenced the above genes of the evolved strain $\triangle \mathrm{APE} 6937$ and compared the results with sequences of the same genes from C. glutamicum ATCC 13032. Analysis of the sequences of the pgi, pfkA, gapA, pyk, pyc, gltA, gdh, argB, and argJ genes in the evolved strain failed to identify any mutations relative to the parent strain.

\section{Genetic modification of the evolved strain}

The results shown in Figure 2A suggest that expression of the $\arg B$ gene may be the bottleneck for L-ornithine production by the evolved strain. Thus, we first overexpressed either of the C. glutamicum or E. coli argB genes in the evolved strain. Over-expression of either of the two $\arg B$ genes indeed enhanced L-ornithine concentration and content, with over-expression of $C$. glutamicum argB increasing levels of L-ornithine concentration to a greater degree than that achieved by the over-expression of E. coli argB (Table 1).

The expression of the arg operon for control of the L-ornithine biosynthesis pathway is regulated by the arginine repressor ArgR. In addition, the DNA-binding affinity of ArgR to the upstream of $\operatorname{argB}$ gene was suggested to play an important role in L-ornithine biosynthesis in C. glutamicum [25]. Deletion of the $\operatorname{argR}$ gene is another strategy for enhancing the level of expression of the $\arg$ operon. Thus, we deleted the $\arg R$ gene of the evolved strain C. glutamicum $\triangle$ APE6937 to generate $C$. glutamicum $\triangle$ APE6937R42. As expected, C. glutamicum $\triangle \mathrm{APE} 6937 \mathrm{R} 42$ produced $17.3 \pm 0.4 \mathrm{~g} / \mathrm{L}$ of L-ornithine (Table 1). The concentration of L-ornithine was $27 \%$ higher than that of C. glutamicum $\triangle$ APE6937.

To investigate the mechanism of L-ornithine production in C. glutamicum $\triangle$ APE6937R42, we analysed the transcriptional levels of the genes that encode enzymes involved in L-ornithine biosynthesis in C. glutamicum $\triangle \mathrm{APE} 6937 \mathrm{R} 42$ by using qRT-PCR, and compared the data with that obtained in $C$. glutamicum $\triangle \mathrm{APE}$ (Figure 2B). Deletion of the $\operatorname{argR}$ gene promoted the upregulations of the transcript levels of the $p g i, p f k A$, $\arg B$, and $\operatorname{argJ}$ genes. The respective transcriptional levels of the $p g i, p f k A, \operatorname{argB}$, and $\operatorname{argJ}$ genes in C. glutamicum $\triangle$ APE6937R42 are about 5.6-, 5.0-, 9.4-, and 16.6-fold $(p<0.05)$ higher than those in the parent strain $C$. glutamicum $\triangle \mathrm{APE}$. In contrast, the respective levels of the same transcripts in C. glutamicum $\triangle \mathrm{APE} 6937$ are only about 3.7-, 3.5-, 2.3-, and 4.0-fold higher $(p<0.05)$ than those in the parent strain C. glutamicum $\triangle \mathrm{APE}$ (Figure 2A).

Three reactions in the L-ornithine biosynthesis pathway involve NADPH. These are the reactions catalysed by NADP-dependent isocitrate dehydrogenase, NADPdependent glutamate dehydrogenase, and NADP-dependent N-acetyl-gamma-glutamyl-phosphate reductase. To analyse the effect of NADPH availability on L-ornithine accumulation, we deleted the $\operatorname{argR}$ gene of the parent strain C. glutamicum $\triangle \mathrm{APE}$ to obtain C. glutamicum $\triangle \mathrm{APER}$, and then analysed the NADPH contents of the two strains. As expected, C. glutamicum $\triangle \mathrm{APE6937R42}$ produced more NADPH and L-ornithine than $C$. glutamicum $\triangle \mathrm{APER}$ (Table 2). To better understand the effect of NADPH, we compared the transcript levels of the genes involved in NADPH synthesis in the $C$. glutamicum strains $\triangle \mathrm{APE} 6937 \mathrm{R} 42$ and $\triangle \mathrm{APER}$. The results are presented in Figure 3. In C. glutamicum $\triangle \mathrm{APE} 6937 \mathrm{R} 42$, the genes involved in NADPH synthesis (zwf, gnd, and icd) were upregulated by 3.8-, 2.7- and 2.5 -fold, respectively $(p<0.05)$. The $p p n k$ gene was also upregulated by 1.8 -fold $(p<0.05)$. Therefore, we examined whether the increased NADPH levels are caused by the upregulations of the transcriptional levels of these genes in C. glutamicum $\triangle \mathrm{APE6937R42.} \mathrm{We} \mathrm{over-}$ expressed these genes in C. glutamicum $\triangle \mathrm{APER}$. The results are presented in Table 3. Over-expression of the $z w f$, gnd and $p p n K$ genes indeed increased the concentration of NADPH in C. glutamicum $\triangle \mathrm{APER}$. However, only over-expression of the $p p n K$ gene promoted Lornithine production. It suggests that only the increased NADPH level caused by the elevated transcriptional level of the $p p n K$ gene promoted L-ornithine production.

\section{Fermentation of the strain generated by metabolic evolution}

For a more detailed view on L-ornithine production, C. glutamicum $\triangle \mathrm{APE} 6937 \mathrm{R} 42$ was cultured in a 5-L bioreactor (Figure 4), and was found to grow in a diauxic manner. The maximum L-ornithine concentration (24.1 \pm $1.5 \mathrm{~g} / \mathrm{L})$ and yield $(0.3 \mathrm{~g} / \mathrm{g})$ was obtained at $33 \mathrm{~h}$, at which time all glucose in the medium had been consumed.

\section{Discussion}

In this study, we first deleted the speE gene to enhance L-ornithine production (Table 1). Spermidine synthase encoded by speE catalyzes the formation of spermidine from putrescine. Although the genes involved in the biosynthesis of putrescine remain unknown, cells of $C$. glutamicum contain putrescine and polyaminies [26]. The deletion of the speE gene blocked putrescine to be

Table 2 Concentrations of NADPH in the different strains

\begin{tabular}{llll}
\hline Strain & OD $_{600}$ & NADPH $(\mu \mathrm{M})$ & $\begin{array}{l}\text { L-ornithine } \\
\text { concentration } \\
(\mathbf{g} / \mathbf{L})\end{array}$ \\
\hline C. glutamicum $\triangle \mathrm{APE6937R42}$ & $22.4 \pm 1.0$ & $34.2 \pm 0.2$ & $17.0 \pm 0.6$ \\
\hline C. glutamicum $\triangle \mathrm{APER}$ & $13.7 \pm 0.3$ & $11.6 \pm 0.2$ & $12.4 \pm 0.6$ \\
\hline
\end{tabular}




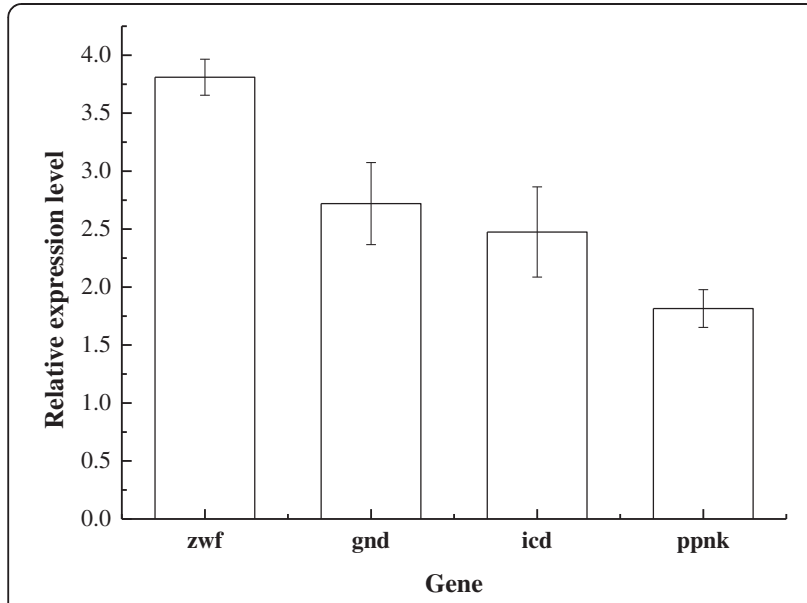

Figure 3 Levels of transcripts involved in NADPH biosynthesis in C. glutamicum $\triangle \mathrm{APE} 6937 \mathrm{R} 42$ compared with those in C. glutamicum $\triangle \mathrm{APER}$ grown at $\mathbf{5 4} \mathrm{h}$ in shake flasks. Abundances of transcripts in $\triangle A P E 6937 R 42$, determined using qRT-PCR, were normalised relative to levels of the same transcript in $\triangle A P E R$.

converted into spermidine and might alleviate the degradation of L-ornithine. However, the real reason of promoting L-ornithine production by the deletion of the speE gene should be further investigated.

Sequence data of the nine genes of C. glutamicum $\triangle$ APE6937 we characterised at the transcript level failed to uncover any mutations in the evolved strain. It is possible that mutations in other genes may have conferred the observed phenotypes. These might include other genes that encode enzymes responsible for L-ornithine biosynthesis or transcription factors that regulate the expression of the sequenced genes. Kutyna et al. also reported that there were no apparent mutations in the Saccharomyces cerevisiae B2-c3 they evolved to generate elevated yields of glycerol [27]. Further work will be required to identify the genetic determinants of these traits.

In C. glutamicum $\triangle \mathrm{APE} 6937$ and $\triangle \mathrm{APE} 6937 \mathrm{R} 42$, elevated transcriptional levels of the genes involved in the upstream pathway of glutamate biosynthesis ( $p g i, p f k A$, gap, $p y k, p y c, g l t A$ and $g d h$, Figure 2) indicated increased

Table 3 Effect of over-expression of gene in C. glutamicum $\triangle$ APER on L-ornithine production

\begin{tabular}{llll}
\hline Plasmid & OD $_{600}$ & NADPH $(\mu \mathrm{M})$ & $\begin{array}{l}\text { L-Ornithine } \\
\text { concentration }(\mathbf{g} / \mathbf{L})\end{array}$ \\
\hline pEC-XK99E & $14.6 \pm 0.1^{*}$ & $1.2 \pm 0.15^{*}$ & $14.2 \pm 0.4^{*}$ \\
\hline pEC-zwf & $14.3 \pm 1.3$ & $6.1 \pm 0.2^{*}$ & $14.6 \pm 0.5$ \\
\hline pEC-ppnk & $11.1 \pm 0.6^{*}$ & $6.2 \pm 0.2^{*}$ & $15.4 \pm 0.4^{*}$ \\
\hline pEC-gnd & $14.6 \pm 1.6$ & $3.1 \pm 0.2^{*}$ & $14.4 \pm 0.5$ \\
\hline pEC-pntAB & $22.9 \pm 1.0^{*}$ & $7.4 \pm 0.4^{*}$ & $17.6 \pm 0.4^{*}$ \\
\hline
\end{tabular}

*Significantly different from the control strain.

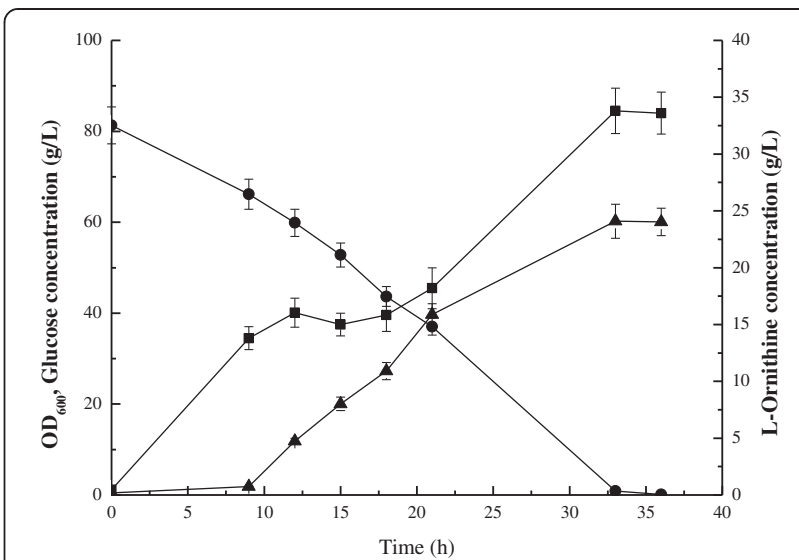

Figure 4 Batch culture of $C$. glutamicum $\triangle \mathrm{APE} 6937 \mathrm{R} 42$ in $5 \mathrm{~L}$ bioreactor. $(\bullet)$ glucose; $(\bullet) \mathrm{OD}_{600}(\mathbf{\Delta})$ L-ornithine.

availability of endogenous glutamate compared with the parental strain. Pyruvate kinase is a major bottleneck for glutamate production, and over-expression of the pyc gene improved glutamate production in C. glutamicum ATCC 13032 [28]. Shirai et al. reported that the fluxes of the reactions catalysed by Pgi, PfkA, Gap, Pyk, Pyc, GltA, and Gdh were increased with glutamate production in C. glutamicum [29]. In our previous paper [15], these enzymes were more abundant in C. glutamicum engineered to overproduce L-ornithine than in wild-type C. glutamicum. It is thought that increasing the availability of endogenous glutamate might increase Lornithine production. Lee and Cho reported that the availability of glutamate was a rate-limiting factor in Lornithine accumulation, and that addition of glutamate in the media increased L-ornithine production in engineered $E$. coli [8]. However, the same group reported that the intracellular concentration and supply of glutamate is not a rate-limiting step for L-ornithine production in an L-ornithine-producer C. glutamicum SJ8074 owing to the presence of rate limiting steps in Lornithine biosynthesis downstream of glutamate synthesis in C. glutamicum SJ8074 [9]. They also reported that the increased availability of glutamate might increase Lornithine accumulation in certain genetic backgrounds (e.g., that of the L-ornithine-producer C. glutamicum SJ8039) [9]. The transcriptional levels of the $\arg B$ and $\operatorname{argJ}$ genes were much higher than those of the genes that encode enzymes that act upstream of glutamate in C. glutamicum $\triangle \mathrm{APE} 6937 \mathrm{R} 42$ (Figure 2B). This indicates that there is no rate-limiting step in L-ornithine synthesis downstream of the synthesis of glutamate in $C$. glutamicum $\triangle \mathrm{APE} 6937 \mathrm{R} 42$. Thus, the elevated transcriptional levels of the genes involved in the upstream pathway of glutamate biosynthesis may be one reason of the increased L-ornithine production in C. glutamicum $\triangle$ APE6937R42. 
This study demonstrated that NADPH availability and L-ornithine production are strongly correlated. Production of L-ornithine requires $2 \mathrm{~mol}$ of NADPH per mole of L-ornithine produced by C. glutamicum. Increases in the levels of $z w f$, gnd, and icd transcripts can increase NADPH availability in C. glutamicum $\triangle$ APE6937R42. However, increased levels of $z w f$ and gnd transcripts can drive the carbon metabolic flux from the EmbdenMeyerhof-Parnas pathway to the pentose phosphate (PP) pathway. Moreover, given that the PP pathway is coupled with $\mathrm{CO}_{2}$ production, direct enhancement of the PP pathway may result in release of $\mathrm{CO}_{2}$, thereby decreasing the yield of L-ornithine. Thus, enhanced carbon flux through the PP pathway, caused by the upregulation of $z w f$ and gnd at the transcriptional level, inhibits Lornithine production. Our results also demonstrated this point. Over-expression of the $z w f$ and gnd genes could not increase L-ornithine production in C. glutamicum $\triangle \mathrm{APER}$ although it could enhance NADPH concentration (Table 3). These suggest that the increased level of L-ornithine production in the evolved strain C. glutamicum $\triangle \mathrm{APE} 6937 \mathrm{R} 42$ was not caused by the increased levels of $z w f$ and gnd transcripts.

ATP-dependent NAD kinase encoded by $p p n K$ catalyzes the phosphorylation of NAD to NADP. Increased transcriptional levels of $p p n K$ increased the size of the NADP pool, thus potentially increasing the abundance of NADPH. Our results demonstrated that the increased level of $p p n K$ transcript indeed enhanced the abundance of NADPH in the evolved strain C. glutamicum $\triangle$ APE6937R42 (Figure 3 and Table 2). Lindner et al. reported that over-expression of ppnk improved L-lysine production in C. glutamicum by $12 \%$ [30]. Overexpression of nadk, which encodes NAD kinase, increased the NADPH/NADP ratio, which in turn enhanced thymidine biosynthesis in E. coli [31]. Our result also demonstrated that over-expression of the $p p n K$ gene enhanced Lornithine production in C. glutamicum $\triangle \mathrm{APER}$. Thus, the elevated level of $p p n K$ transcript that increase the availability of NADPH may be another reason of increased Lornithine production in C. glutamicum $\triangle \mathrm{APE} 6937 \mathrm{R} 42$.

Other strategies have been developed to improve NADPH availability. Over-expression of E. coli pntAB genes, which encode a membrane-bound transhydrogenase enhanced NADPH availability, and thus increased L-lysine levels in C. glutamicum [32]. In this study, overexpression of E. coli pntAB genes enhanced NADPH availability (about 5.2-fold), and thus increased L-ornithine levels $(23.7 \%)$ in C. glutamicum $\triangle$ APER (Table 3). Simultaneous chromosomal overexpression of transhydrogenase $(p n t A B)$ and NAD kinase $(y f j B)$ genes had a effect on increasing NADPH supply and improving anaerobic isobutanol production [33]. Replacement of the endogenous NAD-dependent glyceraldehyde 3-phosphate dehydrogenase with the NADP-dependent glyceraldehyde 3-phosphate dehydrogenase from Streptococcus mutans also increased both NADPH availability and L-lysine production in C. glutamicum [34]. The inactivation of the gluconate kinase gene ( $g n t K)$ led to a $51.8 \%$ increase in intracellular NADPH concentration and a $49.9 \%$ increase in L-ornithine production [12]. These strategies may be useful for further improving Lornithine production in C. glutamicum $\triangle \mathrm{APE} 6937 \mathrm{R} 42$.

To the best of our knowledge, this is the first report of the use of metabolic evolution engineering to increase production of L-ornithine by $C$. glutamicum. The yield of our engineered stain $(24.1 \mathrm{~g} / \mathrm{L})$ is unprecedented in any engineered C. glutamicum strain of which we are aware, including that described in our previous paper $(18.17 \mathrm{~g} / \mathrm{L})$ [16] and that reported by Hwang and Cho (13.16 g/L) [12]. To date, the highest titre of L-ornithine reported in the literature was $74 \mathrm{~g} / \mathrm{L}$, as reported by Lee et al. [6]. Those researchers achieved this yield by using a 7-L fed-batch fermentation process with a glucosefeeding strategy and an L-arginine auxotrophic mutant of Brevibacterium ketoglutamicum ATCC 21092. The titre of this auxotrophic mutant, which was generated using classical mutagenesis, was only $2 \mathrm{~g} / \mathrm{L}$ in batch culture [35]. This suggests that the yield of the new strains described in this study may be enhanced by growth using fed-batch fermentation technology.

\section{Conclusion}

We first deleted the speE gene of $C$. glutamicum ATCC 13032 ( $\triangle \operatorname{argF} \triangle p r o B)$, then evolved by a growth-based selection process for 70 passages to generate C. glutamicum $\triangle \mathrm{APE} 6937$, and finally deleted the $\operatorname{argR}$ gene of the evolved strain to obtain C. glutamicum $\triangle$ APE6937R42. The C. glutamicum $\triangle$ APE6937R42 strain produced 24.1 $\mathrm{g} / \mathrm{L}$ of L-ornithine in a 5 -L bioreactor, a level unprecedented in any engineered strain. It has been demonstrated that the increased L-ornithine production in C. glutamicum $\triangle \mathrm{APE} 6937 \mathrm{R} 42$ is dependent on the increased availabilities of glutamate caused by the elevated levels of transcripts involved in the upstream pathway of glutamate biosynthesis and the increased availabilities of NADPH caused by the elevated level of $p p n K$ transcript. The availability of NADPH plays an important role in L-ornithine production in C. glutamicum.

\section{Methods}

Strains, primers and plasmids

All strains and plasmids used in this study are listed in Table 4. The C. glutamicum strain ATCC 13032 $(\triangle a r g F \Delta p r o B)$ [15] was used as the starting strain for L-ornithine production. Primers used in this study are listed in Table 5. L-ornithine was purchased from Sigma. 
Table 4 Strains and plasmids used in this study

\begin{tabular}{|c|c|c|}
\hline Strain, plasmid & Properties/sequence & Source/reference \\
\hline \multicolumn{3}{|l|}{ Strain } \\
\hline Escherichia coli DH5a & supE44, hsdR17, recA1, thi-1, endA1, lacZ, gyrA96, relA1 & Invitrogen \\
\hline \multicolumn{3}{|l|}{ C. glutamicum } \\
\hline ATCC 13032 & Wild-type & ATCC \\
\hline ATCC 13032 (4argFAproB) & C. glutamicum ATCC 13032, $\triangle \arg F, \Delta p r o B$ & 15 \\
\hline$\triangle \mathrm{APE}$ & C. glutamicum ATCC 13032, $\triangle$ argF, $\Delta$ proB, $\Delta$ speE & This study \\
\hline$\triangle \mathrm{APE} 6937$ & The evolved strain of ATCC 13032 (UargFAproBAspeE) & This study \\
\hline$\triangle \mathrm{APE} 6937 \mathrm{R} 42$ & $\triangle A P E 6937, \triangle \arg R$ & This study \\
\hline$\triangle \mathrm{APER}$ & C. glutamicum ATCC 13032, $\Delta$ argF, $\Delta$ proB, $\triangle$ speE, $\triangle \arg R$ & This study \\
\hline pK18mobsacB & $\begin{array}{l}\text { sacB, lacZa, Kmr, mcs mobilizable vector, allows for selection of double } \\
\text { crossover C. glutamicum }\end{array}$ & 39 \\
\hline pK-JL & pK18mobsacB derivative, sacB under the control of tac- $M$ promoter, $\mathrm{Km}^{r}$, & This study \\
\hline pMD18-T & TA cloning vector, Amp ${ }^{r}$ & TaKaRa \\
\hline $\mathrm{pK}-\Delta \arg R$ & pK-JL with 506 bp deletion of the $\arg R$ gene & This study \\
\hline pEC-XK99E & C. glutamicum-E. coli shuttle expression vector, Kan $^{r}$ & 41 \\
\hline $\mathrm{pEC}-\arg \mathrm{B}_{\mathrm{CG}}$ & pEC-XK99E containing the $\operatorname{argB}$ gene from C. glutamicum & This study \\
\hline $\mathrm{pEC}-\arg \mathrm{B}_{\mathrm{EC}}$ & pEC-XK99E containing the $\operatorname{argB}$ gene from E. coli & This study \\
\hline pEC-zwf & pEC-XK99E containing the zwf gene from C. glutamicum & This study \\
\hline pEC-ppnK & pEC-XK99E containing the ppnk gene from C. glutamicum & This study \\
\hline pEC-gnd & pEC-XK99E containing the gnd gene from C. glutamicum & This study \\
\hline pEC-pntAB & pEC-XK99E containing the gnd gene from E. coli & This study \\
\hline
\end{tabular}

\section{L-ornithine production in shake flasks}

For L-ornithine fermentations, a $1.0-\mathrm{mL}$ sample of the seed culture that had been grown at $150 \mathrm{rpm}$ and $30^{\circ} \mathrm{C}$ for 12 hours was inoculated into $10 \mathrm{~mL}$ of the fermentation medium in a $100-\mathrm{mL}$ flask and incubated at $30^{\circ} \mathrm{C}$ and $150 \mathrm{rpm}$ for 72 hours. Each litre of the seed medium contained $25 \mathrm{~g}$ of glucose, $10 \mathrm{~g}$ of yeast extract, $10 \mathrm{~g}$ of corn steep liquor, $15 \mathrm{~g}$ of $\left(\mathrm{NH}_{4}\right)_{2} \mathrm{SO}_{4}, 2.5 \mathrm{~g}$ of $\mathrm{MgSO}_{4} \cdot 7 \mathrm{H}_{2} \mathrm{O}, 1 \mathrm{~g}$ of $\mathrm{KH}_{2} \mathrm{PO}_{4}, 0.5 \mathrm{~g}$ of $\mathrm{K}_{2} \mathrm{HPO}_{4}, 0.5 \mathrm{~g}$ of $\mathrm{Na}_{2} \mathrm{HPO}_{4}$, and $10 \mathrm{~g}$ of $\mathrm{CaCO}_{3}$. Each litre of the fermentation medium contained $100 \mathrm{~g}$ of glucose, $20 \mathrm{~g}$ of corn steep liquor, $50 \mathrm{~g}$ of $\left(\mathrm{NH}_{4}\right)_{2} \mathrm{SO}_{4}, 2.5 \mathrm{~g}$ of $\mathrm{MgSO}_{4} \cdot 7 \mathrm{H}_{2} \mathrm{O}$, $1 \mathrm{~g}$ of $\mathrm{KH}_{2} \mathrm{PO}_{4}, 0.5 \mathrm{~g}$ of $\mathrm{K}_{2} \mathrm{HPO}_{4}, 0.5 \mathrm{~g}$ of $\mathrm{Na}_{2} \mathrm{HPO}_{4}, 20$ $\mathrm{mg}$ of $\mathrm{FeSO}_{4} \cdot 7 \mathrm{H}_{2} \mathrm{O}, 20 \mathrm{mg}$ of $\mathrm{MnSO}_{4} \cdot 4 \mathrm{H}_{2} \mathrm{O}, 2 \mathrm{~g}$ of molasses, $1 \mathrm{~mL}$ of Tween-80, and $10 \mathrm{~g}$ of $\mathrm{CaCO}_{3}$. The initial $\mathrm{pH}$ of both media described above was adjusted to 7.0 .

\section{Adaptive evolution}

The adaptive evolution process is presented in Figure 1. Adaptive evolution was conducted in a test tube that contained $5 \mathrm{~mL}$ of fermentation medium supplemented with $50 \mathrm{~g} / \mathrm{L}$ glucose and $15 \mathrm{~g} / \mathrm{L}$ L-ornithine, and incubated at $30^{\circ} \mathrm{C}$ and $200 \mathrm{rpm}$. Cultures were serially passed into fresh medium (initial $\mathrm{OD}_{600}$ of 0.2 ) daily. After repeating this transfer procedure 30 times, the culture was then sequentially transferred to fermentation medium containing $70 \mathrm{~g} / \mathrm{L}$ glucose. The daily transfer procedure at the glucose concentration was repeated 20 times. Finally, the culture was then sequentially transferred to fermentation medium with $100 \mathrm{~g} / \mathrm{L}$ glucose, and the daily transfer procedure was repeated 20 times. Cultures were frozen and stored at $-80^{\circ} \mathrm{C}$ at every 10 passages throughout adaptive evolution.

After the 70-day adaptive evolution process, cultures stored at $-80^{\circ} \mathrm{C}$ were spread onto LB medium plates (10 g/L tryptone, $5 \mathrm{~g} / \mathrm{L}$ yeast extract, $10 \mathrm{~g} / \mathrm{L} \mathrm{NaCl})$. Single colony was transferred to MM medium plates $(5 \mathrm{~g} / \mathrm{L}$ of glucose, $1 \mathrm{~g} / \mathrm{L}$ of $\left(\mathrm{NH}_{4}\right)_{2} \mathrm{SO}_{4}, 0.5 \mathrm{~g} / \mathrm{L}$ of sodium citrate, $0.1 \mathrm{~g} / \mathrm{L}$ of $\mathrm{MgSO}_{4} \cdot 7 \mathrm{H}_{2} \mathrm{O}, 4.5 \mathrm{~g} / \mathrm{L} \mathrm{K} \mathrm{KPO}_{4}$, and $10.5 \mathrm{~g}$ of $\left.\mathrm{KH}_{2} \mathrm{PO}_{4}(\mathrm{pH} 7.0)\right)$ that was supplemented with $5 \mathrm{~g} / \mathrm{L} \mathrm{L}$-ornithine and $5 \mathrm{~g} / \mathrm{L} \mathrm{L}$-arginine. Only colonies that grew on the LB medium plates were further cultured in shake flasks to evaluate their levels of L-ornithine production.

\section{Quantitative real-time PCR (qRT-PCR)}

Total RNA from C. glutamicum cells grown for $54 \mathrm{~h}$ in shake flasks was isolated using an RNA extraction kit (Dongsheng Biotech, Guangzhou, China), following the manufacturer's instructions. The first-strand cDNA was synthesized using an All-in-One ${ }^{\mathrm{Tn}}$ First-Strand cDNA Synthesis Kit (GeneCopoeia, Guangzhou, China). The qRT-PCR was performed with the All-in-One ${ }^{\text {tax }}$ qPCR 
Table 5 Primers used in this study

\begin{tabular}{|c|c|c|}
\hline Primer & Sequence* & Purpose \\
\hline sacBF & $\begin{array}{l}\text { cggcgactagttgagctgttgacaattaatcatcgtgtggtaccatgtgtgg } \\
\text { aattgtgagcggataacaattccgcgggttctttaggeccgtagtct (Spel,Sacll) }\end{array}$ & PCR for the sacB gene \\
\hline $\mathrm{sacBR}$ & gccgcgatatctctcgtgatggcaggtt (EcoRV) & PCR for the $s a c B$ gene \\
\hline pk18msF & gcgccgatatcgttcgtctggaaggcagta (EcoRV) & $\begin{array}{l}\text { PCR for the backbone of pK18mobsacB except for } \\
\text { the } s a c B \text { gene }\end{array}$ \\
\hline pk18msR & gcgcgactagtgcatgggcataaagttgc (Spel) & $\begin{array}{l}\text { PCR for the backbone of pK18mobsacB except for } \\
\text { the sacB gene }\end{array}$ \\
\hline $\operatorname{argR-F5}$ & cgctggatcctttaagcacggcgttattt $($ BamHI) & PCR for the upstream fragment of the $\arg R$ gene \\
\hline $\operatorname{argR-R5}$ & cggtctagatgcgagtcacgggattta (Xbal) & PCR for the upstream fragment of the $\arg R$ gene \\
\hline $\operatorname{argR-F3}$ & cggtctagaggtaaggtataacccgagtgt (Xbal) & PCR for the downstream fragment of the $\arg R$ gene \\
\hline $\operatorname{argR-R3}$ & cgatgtcgacgacttgatgcccacgaga (Sall) & PCR for the downstream fragment of the $\arg R$ gene \\
\hline GargBF & cgctctagaaaggacacaggcatgaatgact (Xbal) & PCR for the $\arg B$ gene from $C$. glutamicum \\
\hline GargBR & cgggtcgacttacagttccccatcctt (Sall) & PCR for the $\operatorname{argB}$ gene from C. glutamicum \\
\hline EargBF & cgttctagaaggaggggtgcaatgatgaat (Xbal) & PCR for the $\arg B$ gene from E. coli \\
\hline EargBR & gcggtcgaccttaagctaaaatccg (Sall) & PCR for the $\arg B$ gene from E. coli \\
\hline zWf-F & ccgcctctagaaaggagaccatcatgagcacaaacac (Xbal) & PCR for the zwf gene from C. glutamicum \\
\hline$z w f-R$ & cggtagtcgacccctaaattatggectgc (Sall) & PCR for the zwf gene from C. glutamicum \\
\hline ppnK-F & gccatgaattcaaggacgcaataatgactgcacccacgaa (EcoRl) & PCR for the ppnK gene from C. glutamicum \\
\hline ppnK-R & ccgccgagctccgaattaccccgctgac (Sacl) & PCR for the ppnK gene from C. glutamicum \\
\hline gnd-F & gcgatggtaccaaggagaccactatgccgtcaagtacgat(Kpnl) & PCR for the gnd gene from C. glutamicum \\
\hline gnd-R & ccgcgtctagaaaaggagagcctttaagct (Xbal) & PCR for the gnd gene from C. glutamicum \\
\hline pntAB-F & cagggtacctcatcaataaaaccg(Kpnl) & PCR for the pntAB gene from E. coli \\
\hline pntAB-R & cgtctgcagttacagagctttcag(Pstl) & PCR for the pntAB gene from E. coli \\
\hline qpgiF & cccttctattctcggtgc & qRT-PCR for $p g i$ \\
\hline qpgiR & aggtcatttgcctgctgt & qRT-PCR for pgi \\
\hline qpfkAF & tatccctgttgtcggtgtc & qRT-PCR for $p f k A$ \\
\hline qpfkAR & gtgagattcagcggtggt & qRT-PCR for $p f k A$ \\
\hline qgapF & ggaagttgaatacgacgatga & qRT-PCR for gap \\
\hline qgapR & gcccagtccaggttcttt & qRT-PCR for gap \\
\hline qpycF & accgccacgaaatccc & qRT-PCR for $p y c$ \\
\hline qpycR & aacggctgcgtagttgtct & qRT-PCR for $p y c$ \\
\hline qpykF & ccgtgcagtcggtattct & qRT-PCR for $p y k$ \\
\hline qpykR & gcgttccctctacatcgt & qRT-PCR for $p y k$ \\
\hline qgltAF & cgggaatcctgcgttac & qRT-PCR for g/tA \\
\hline qgltAR & tggcgaatctcgtcgtt & qRT-PCR for glt $A$ \\
\hline qgdhF & ccgccacatcggtgagta & qRT-PCR for gdh \\
\hline qgdhR & agccatgcgacggtagt & qRT-PCR for gdh \\
\hline qargBF & ggtttggtcggagacatca & qRT-PCR for $\arg B$ \\
\hline qargBR & gcctggagcaatcgtagag & qRT-PCR for $\arg B$ \\
\hline qargJF & cctgacatggcgttgg & qRT-PCR for arg」 \\
\hline qargJR & ctcggctcaccttcaca & qRT-PCR for arg J \\
\hline qzwfF & acccgcaggataaacga & qRT-PCR for $z w f$ \\
\hline qzwfR & gctagatcataaatggc & qRT-PCR for zwf \\
\hline qppnkF & gtttaccgaccgacttgtg & qRT-PCR for ppnk \\
\hline qppnkR & gctgacctgggatctttatt & qRT-PCR for ppnk \\
\hline qicdF & aggaccagggctacgacat & qRT-PCR for icd \\
\hline qicdR & gcggaacccttaacagc & qRT-PCR for icd \\
\hline qgndF & aaccgcagcactgacaaa & qRT-PCR for gnd \\
\hline
\end{tabular}


Table 5 Primers used in this study (Continued)

\begin{tabular}{lll}
\hline qgndR & cagggatgctacgaactct & qRT-PCR for gnd \\
\hline $16 \mathrm{~s}-\mathrm{F}$ & tcgatgcaacgcgaagaac & qRT-PCR for 16srRNA \\
\hline $16 \mathrm{~s}-\mathrm{R}$ & gaaccgaccacaagggaaaac & qRT-PCR for 16srRNA \\
\hline
\end{tabular}

*Restriction enzyme sites are underlined.

Mix kit (GeneCopoeia, Guangzhou, China) on an iCycler iQ5 Real Time PCR system (Bio-Rad Laboratories, USA). 100 ng of cDNA was used as template. The PCR conditions were: $95^{\circ} \mathrm{C}$ for $10 \mathrm{~min}$, followed by 45 cycles of denaturation at $95^{\circ} \mathrm{C}$ for $10 \mathrm{~s}$, annealing at $60^{\circ} \mathrm{C}$ for $20 \mathrm{~s}$, and extension at $72^{\circ} \mathrm{C}$ for $15 \mathrm{~s}$. The primers for qRT-PCR are presented in Table 5. The quantification technique used to analyse data was the $2^{-\Delta \Delta \mathrm{Ct}}$ method described by Livak and Schmittgen [36]. The data were normalized using expression of $16 \mathrm{~S}$ rRNA.

\section{Gene knockout}

Chromosomal DNA of C. glutamicum was isolated as described by Eikmanns et al. [37]. The preparation of competent cells and electroporation for C. glutamicum was performed as described by Van de Rest et al. [38]. The correct mutants of C. glutamicum were confirmed by PCR.

The lethality of the $s a c B$ gene in corynebacteria depends on its expression levels. Therefore, a 1.85-kb DNA fragment containing the $\operatorname{sacB}$ gene cluster was amplified by PCR using the primers $\mathrm{sacBF}$ and $\mathrm{sacBR}$ (Table 5), and the plasmid pK18mobsacB [39] as template. This converted the native promoter of the $s a c B$ gene cluster to a $t a c-M$ promoter, which is a strong promoter in corynebacteria [40]. The entire backbone of pK18mobsacB, except for the $s a c B$ gene, was amplified using the primers pk18msF and pk18msR (Table 5). The two fragments were digested with SpeI and EcoRV, and ligated together to form the inducible suicide vector $\mathrm{pK}$ JL (5,570 bp).

Disruption of the gene was performed using the nonreplicable integration vector $\mathrm{pK}-\mathrm{JL}$, which allows for marker-free deletion of the target gene [39]. The flanking sequence of the $\arg R$ gene (1,153 bp and $921 \mathrm{bp})$ was amplified from the genomic DNA of C. glutamicum using the primers argR-F5/argR-R5 and $\operatorname{argR-F3/argR-~}$ $\mathrm{R} 3$, and ligated separately into pMD18-T. The two fragments were excised using BamHI/XbaI and XbaI/SalI, respectively, and then ligated into the $B a m H I / S a l I$ sites of $\mathrm{pK}-\mathrm{JL}$ to obtain the non-replicable integration vector pK- $\Delta$ argR, which contains an internal 506-bp deletion in the $\arg R$ gene. The above nonreplicable integration vector $\mathrm{pK}-\Delta \operatorname{argR}$ was transferred into C. glutamicum to disrupt the site-specific gene using the protocol described by Schäfer et al. [39].

\section{Plasmid construction}

The $\arg B$ gene, which encodes acetylglutamate kinase, was amplified from the genomic DNA of C. glutamicum and E. coli, using the primer pairs GargBF/GargBR and EargBF/EargBR, respectively. The fragments were ligated separately into the pMD18-T vector. Both fragments were excised using $\mathrm{XbaI} / \mathrm{SalI}$ and then inserted into the XbaI/SalI sites of pEC-XK99E [41] to obtain the overexpression vectors $\mathrm{pEC}-\operatorname{argB} \mathrm{B}_{\mathrm{CG}}$ and $\mathrm{pEC}-\arg \mathrm{B}_{\mathrm{EC}}$. The $z w f, p p n K$ and gnd gene was amplified from the genomic DNA of C. glutamicum using the corresponding primer pairs (Table 5), and then inserted into the corresponding sites of pEC-XK99E, respectively. The pntAB genes were amplified from the genomic DNA of $E$. coli, using the primer pair pntAB-F/pntAB-R (Table 5) and then inserted into the KpnI/PstI sites of pEC-XK99E.

\section{NADPH assay}

After aerobic cultivation of C. glutamicum on a rotary shaker $(150 \mathrm{rpm})$ at $30^{\circ} \mathrm{C}$ for $54 \mathrm{~h}$, the cells were harvested by centrifugation and washed twice with water. Intracellular NADPH was extracted and quantified using the Enzychrom ${ }^{\mathrm{TM}} \mathrm{NADP}^{+} / \mathrm{NADPH}$ Assay kit (BioAssay Systems, Hayward, CA) following the manufacturer's instructions.

\section{Batch culture in bioreactor}

Batch culture was carried out at $30^{\circ} \mathrm{C}$ in a 5 - $\mathrm{L}$ jar fermentor (Biostat B5, B. Braun, Germany) that contained $3 \mathrm{~L}$ of fermentation medium. To prepare the inocula, 10 $\mathrm{mL}$ of $\mathrm{LB}$ medium was inoculated with a small aliquot of cell glycerol stock that had been stored at $-80^{\circ} \mathrm{C}$, and was cultured overnight at $30^{\circ} \mathrm{C}$. One millilitre of the overnight culture was subsequently transferred into a 250-mL Erlenmeyer flask containing $50 \mathrm{~mL}$ of the seed medium, and incubated for $24 \mathrm{~h}$ at $30^{\circ} \mathrm{C}$ and $150 \mathrm{rpm}$ in a shaking incubator. The seed cultures $(300 \mathrm{~mL})$ were inoculated into the fermenter for batch cultivation. The $\mathrm{pH}$ was maintained at 7.0 by adding $\mathrm{NH}_{4} \mathrm{OH}$. Antifoam was added manually as needed. The aeration rate was $1.0 \mathrm{~L} / \mathrm{L} / \mathrm{min}$ and the agitation rate was $400 \mathrm{rpm}$. Samples were periodically taken for the measurements of $\mathrm{OD}_{600}$, residual glucose concentration, and L-ornithine concentration. Fermentation experiments were carried out in duplicate. 


\section{Assays of cell growth, L-ornithine, and glucose}

Cell growth was monitored by measuring the optical density of the culture at $600 \mathrm{~nm}$ (OD600) using a spectrophotometer (Shimadzu Corporation, Japan) after dilution of the culture with $0.2 \mathrm{~mol} / \mathrm{L} \mathrm{HCl}$ to dissolve $\mathrm{CaCO}_{3}$. L-Ornithine concentrations were determined by colorimetry, using ninhydrin as described previously [42]. Glucose concentration was determined by glucose oxidase using a glucose assay kit (Shanghai Rongsheng Biotech Corporation, China).

\section{Statistical analysis}

All experiments were conducted in triplicate, and data were averaged and presented as the mean \pm standard deviation (SD). One-way analysis of variance (ANOVA) followed by Tukey's test was used to determine significant differences using OriginPro (version 7.5) software. Statistical significance was defined as $p<0.05$.

\section{Competing interests}

The authors declare that they have no competing interests.

\section{Authors' contributions}

LY J carried out most of the experiments. SG C carried out fermentation in $5 \mathrm{~L}$ bioreactor. $Y Y Z$ constructed some expression vectors. JZ $L$ developed the concept and designed the method, led the project and drafted the manuscript. All authors read and approved the final manuscript.

\section{Acknowledgments}

We are grateful to both the National Natural Science Foundation of China (Grant Nos 30970089, 20876181, 21276289) and the Natural Science Foundation of Guangdong Province (Nos 9351027501000003 ,

S2011010001396) for their financial support.

Received: 6 March 2013 Accepted: 31 May 2013

Published: 1 June 2013

\section{References}

1. Cimino F, Maria C, Cittadini D: Mechanism of the protection by L-ornithine-L-aspartate mixture and by L-arginine in ammonia intoxication. Arch Biochem Biophys 1964, 107:499-503.

2. Shi HP, Fishel RS, Efron DT, Williams JZ, Fishel MH, Barbul A: Effect of supplemental ornithine on wound healing. J Surg Res 2002, 106:299-302.

3. Zajac A, Poprzecki S, Zebrowska A, Chalimoniuk M, Langfort J: Arginine and ornithine supplementation increases growth hormone and insulin-like growth factor-1 serum levels after heavy-resistance exercise in strengthtrained athletes. J Strength Cond Res 2010, 24:1082-1090.

4. Choi DK, Ryu WS, Choi CY, Park YH: Production of L-ornithine by arginine auxotrophic mutants of Brevibacterium ketoglutamicum in dual substrate limited continuous culture. J Ferment Bioeng 1996, 81:216-219.

5. Kinoshita S, Nakayama K, Udaka S: The fermentative production of L-ornithine. J Gen Appl Microbiol 1957, 3:276-277.

6. Lee HW, Yoon SJ, Jang HW, Kim CS, Kim TH, Ryu WS, Jung JK, Park YH: Effects of mixing on fed-batch fermentation of L-ornithine. J Biosci Bioeng 2000, 89:539-544.

7. Zhang JF, Wang JB, Huang JM, Zhang J: Breeding of high-yield L-ornithine -producing strain by protoplast fusion. Amino Acids Biotic Resour 2009, 31:53-57.

8. Lee YJ, Cho JY: Genetic manipulation of a primary metabolic pathway for L-ornithine production in Escherichia coli. Biotechnol Let 2006, 28:1849-1856.

9. Hwang JH, Hwang GH, Cho JY: Effect of increased glutamate availability on L-ornithine production in Corynebacterium glutamicum. J Microbiol Biotechnol 2008, 18:704-710.
10. Lee SY, Cho JY, Lee HJ, Kim YH, Min J: Enhancement of ornithine production in proline-supplemented Corynebacterium glutamicum by ornithine cyclodeaminase. J Microbiol Biotechnol 2010, 20:127-131.

11. Hwang $\mathrm{GH}$, Cho JY: Identification of a suppressor gene for the arginineauxotrophic argJ mutation in Corynebacterium glutamicum. J Ind Microbiol Biotechnol 2010, 37:1131-1136.

12. Hwang GH, Cho JY: Implication of gluconate kinase activity in L-ornithine biosynthesis in Corynebacterium glutamicum. J Ind Mcrobiol Biotechnol 2012, 39:1869-1874.

13. Schneider J, Niermann K, Wendisch VF: Production of the amino acids L-glutamate, L-lysine, L-ornithine and L-arginine from arabinose by recombinant Corynebacterium glutamicum. J Biotechnol 2011, 154:191-198.

14. Meiswinkel TM, Gopinath V, Lindner SN, Nampoothiri M, Wendisch VF: Accelerated pentose utilization by Corynebacterium glutamicum for accelerated production lysine, glutamate, ornithine and putrescine. Microb Biotechnol 2013, 6:131-140.

15. Lu DM, Liu JZ, Mao ZW: Engineering of Corynebacterium glutamicum to enhance L-ornithine production by gene knockout and comparative proteomic analysis. Chinese J Chem Eng 2012, 20:731-739.

16. Lu DM, Jiang LY, Chen LA, Liu JZ, Mao ZW: Optimization of fermentation conditions of the engineered Corynebacterium glutamicum to enhance Lornithine production by response surface methodology. J Biotechnol Biomater 2011, 1:116. doi:10.4172/2155-952X.1000116.

17. Fong SS, Palsson BO: Metabolic gene-deletion strains of Escherichia coli evolve to computationally predicted growth phenotypes. Nat Genet 2004, 36:1056-1058.

18. Portnoy VA, Bezdan D, Zengler K: Adaptive laboratory evolution harnessing the power of biology for metabolic engineering. Curr Opin Biotechnol 2011, 22:590-594.

19. Wang Y, Manow R, Finan C, Wang J, Garza E, Zhou S: Adaptive evolution of nontransgenic Escherichia coli KCO1 for improved ethanol tolerance and homoethanol fermentation from xylose. J Ind Microbiol Biotechnol 2011, 38:1371-1377.

20. Wang Z, Gao C, Wang Q, Liang Q, Qi Q: Production of pyruvate in Saccharomyces cerevisiae through adaptive evolution and rational cofactor metabolic engineering. Biochem Eng J 2012, 67:126-131.

21. Fong SS, Burgard AP, Herring CD, Knight EM, Blattner FR, Maranas CD, Palsson BO: In silico design and adaptive evolution of Escherichia coli for production of lactic acid. Biotechnol Bioeng 2005, 91:643-648.

22. Jantama K, Haupt MJ, Svoronos SA, Zhang X, Moore JC, Shanmugam $K T$, Ingram LO: Combining metabolic engineering and metabolic evolution to develop nonrecombinant strains of Escherichia coli C that produce succinate and malate. Biotechnol Bioeng 2008, 99:1140-1153.

23. Zhang X, Jantama K, Moore JC, Shanmugam KT, Ingram LO: Production of L-alanine by metabolically engineered Escherichia coli. Appl Microbiol Biotechnol 2007, 77:355-366.

24. Lu L, Wei L, Zhu K, Wei D, Hua Q: Combining metabolic engineering and adaptive evolution to enhance the production of dihydroxyacetone from glycerol by Gluconobacter oxydans in a low-cost way. Bioresource Technol 2012, 117:317-324.

25. Lee SY, Kim YH, Min J: The effect of ArgR-DNA binding affinity on ornithine production in Corynebacterium glutamicum. Curr Microbiol 2009, 59:483-488.

26. Altenburger $P$, Kämpfer $P$, Akimov VN, Lubitz W, Busse HJ: Polyamine distribution in actinomycetes with group $B$ peptidoglycan and species of the genera Brevibacterium, Corynebacterium, and Tsukamurella. Int J Syst Bacteriol 1997, 47:270-277.

27. Kutyna DR, Varela C, Stanley GA, Borneman AR, Henschke PA, Chambers PJ: Adaptive evolution of Saccharomyces cerevisiae to generate strains with enhanced glycerol production. Appl Microbiol Biotechnol 2012, 93:1175-1184

28. Peters-Wendisch PG, Schiel VF, Wendisch E, Katsoulidis B, Möckel HS, Eikmanns BJ: Pyruvate carboxylase is a major bottleneck for glutamate and lysine production by Corynebacterium glutamicum. J Mol Microbiol Biotechnol 2001, 3:295-300.

29. Shirai T, Fujimura K, Furusawa C, Nagahisa K, Shioya S, Shimizu H: Study on roles of anaplerotic pathways in glutamate overproduction of Corynebacterium glutamicum by metabolic flux analysis. Microb Cell Fact 2007, 6:19. 
30. Lindner SN, Niederholtmeyer H, Schmitz K, Schoberth SM, Wendisch VF: Polyphosphate/ATP-dependent NAD kinase of Corynebacterium glutamicum: biochemical properties and impact of ppnK overexpression on lysine production. Appl Microbiol Biotechnol 2010, 87:583-593.

31. Lee HC, Kim JS, Jang W, Kim SY: High NADPH/NADP ratio improves thymidine production by a metabolically engineered Escherichia coli strain. J Biotechnol 2010, 149:24-32.

32. Kabus A, Georgi T, Wendisch VF, Michael B: Expression of the Escherichia coli pnt $A B$ genes encoding a membrane-bound transhydrogenase in Corynebacterium glutamicum improves L-lysine formation. Appl Microbiol Biotechnol 2007, 75:47-53.

33. Shi A, Zhu X, Lu J, Zhang X: Ma Y: Activating transhydrogenase and NAD kinase in combination for improving isobutanol production. Metab Eng 2013, 16:1-10.

34. Takeno S, Murata R, Kobayashi R, Mitsuhashi S, Ikeda M: Engineering of Corynebacterium glutamicum with an NADPH-generating glycolytic pathway for L-lysine production. Appl Environ Microbiol 2010, 76:7154-7160.

35. Choi DK, Ryu WS, Chung BH, Hwang SO, Park YH: Effect of dilution rate in continuous production of $\mathrm{L}$-ornithine by an arginine auxotrophic mutant. J Ferment Bioeng 1995, 80:97-100.

36. Livak K, Schmittgen TD: Analysis of relative gene expression data using real-time quantitative PCR and the $2^{-\Delta \Delta C t}$ Method. Methods 2001, 25:402-408.

37. Eikmanns BJ, Thum-Schmitz N, Eggeling L, Ludtke KU, Sahm H: Nucleotide sequence, expression, and transcription analysis of the Corynebacterium glutamicum gltA gene encoding citrate synthase. Microbiol 1994, 140:1817-1828.

38. Van der Rest ME, Lange C, Molenaar D: A heat shock following electroporation induces highly efficient transformation of Corynebacterium glutamicum with xenogeneic plasmid DNA. Appl Microbiol Biotechnol 1999, 52:541-545.

39. Schäfer A, Tauch A, Jäger W, Kalinowski J, Thierbach G, Pühler A: Small mobilizable multi-purpose cloning vectors derived from the Escherichia coli plasmids pK18 and pK19: selection of defined deletions in the chromosome of Corynebacterium glutamicum. Gene 1994, 145:69-73.

40. Xu D, Tan Y, Shi F, Wang X: An improved shuttle vector constructed for metabolic engineering research in Corynebacterium glutamicum. Plasmid 2010, 64:85-91.

41. Kirchner $\mathrm{O}$, Tauch $\mathrm{A}$ : Tools for genetic engineering in the amino acidproducing bacterium Corynebacterium glutamicum. J Biotechnol 2003, 104:287-299.

42. Chinard FP: Photometric estimation of proline and ornithine. J Biol Chem 1952, 199:91-95.

\section{doi:10.1186/1472-6750-13-47}

Cite this article as: Jiang et al.: Metabolic evolution of Corynebacterium glutamicum for increased production of L-ornithine. BMC Biotechnology 2013 13:47.

\section{Submit your next manuscript to BioMed Central and take full advantage of:}

- Convenient online submission

- Thorough peer review

- No space constraints or color figure charges

- Immediate publication on acceptance

- Inclusion in PubMed, CAS, Scopus and Google Scholar

- Research which is freely available for redistribution 